\title{
Quantitative Finance Risk MANAGEMENT
}

\author{
A Physicist's Approach
}


This page intentionally left blank 


\title{
Quantitative Finance AND Risk MANagement
}

\section{A Physicist's Approach}

\author{
Jan W Dash
}




\section{Published by}

World Scientific Publishing Co. Pte. Ltd.

5 Toh Tuck Link, Singapore 596224

USA office: Suite 202, 1060 Main Street, River Edge, NJ 07661

UK office: 57 Shelton Street, Covent Garden, London WC2H 9HE

\section{British Library Cataloguing-in-Publication Data}

A catalogue record for this book is available from the British Library.

\section{QUANTITATIVE FINANCE AND RISK MANAGEMENT A Physicist's Approach}

Copyright $\odot 2004$ by World Scientific Publishing Co. Pte. Ltd.

All rights reserved. This book, or parts thereof, may not be reproduced in any form or by any means, electronic or mechanical, including photocopying, recording or any information storage and retrieval system now known or to be invented, without written permission from the Publisher.

For photocopying of material in this volume, please pay a copying fee through the Copyright Clearance Center, Inc., 222 Rosewood Drive, Danvers, MA 01923, USA. In this case permission to photocopy is not required from the publisher.

ISBN $981-238-712-9$

This book is printed on acid-free paper.

Printed in Singapore by Mainland Press 


\section{Dedication}

I dedicate this book to my father and mother, Edward and Honore Dash. They inspired learning and curiosity, and advised never to take anything for granted. 
This page intentionally left blank 


\section{Table of Contents}

PART I: INTRODUCTION, OVERVIEW, AND EXERCISE 1

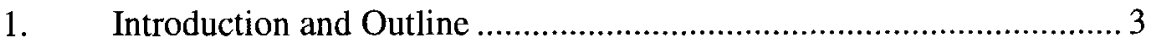

Who/ How/What, "Tech. Index", Messages, Personal Note.................. 3

Summary Outline: Book Contents ..................................................... 5

2. Overview (Tech. Index 1/10) ..................................................... 7

Objectives of Quantitative Finance and Risk Management .................. 7

Tools of Quantitative Finance and Risk Management .......................... 9

The Traditional Areas of Risk Management ...................................... 11

When Will We Ever See Real-Time Color Movies of Risk?.............. 13

Many People Participate in Risk Management .................................... 13

Quants in Quantitative Finance and Risk Management ....................... 15

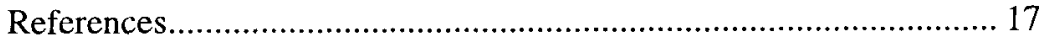

3. An Exercise (Tech. Index 1/10) .................................................... 19

Part \#1: Data, Statistics, and Reporting Using a Spreadsheet............. 19

Part \#2: Repeat Part \#1 Using Programming ........................................ 22

Part \#3: A Few Quick and Tricky Hypothetical Questions................. 23

Messages and Advice....................................................................... 24

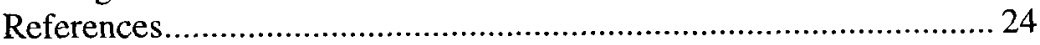

PART II: RISK LAB (NUTS AND BOLTS OF RISK MANAGEMENT) .... 25

4. Equity Options (Tech. Index 3/10) ……......................................... 27

Pricing and Hedging One Option ..................................................... 27

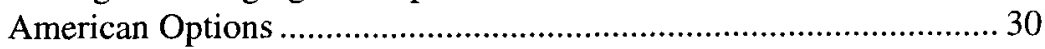

Basket Options and Index Options .................................................... 31

Other Types of Equity Options; Exotics............................................. 33

Portfolio Risk (Introduction) ................................................................... 33

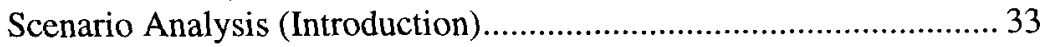

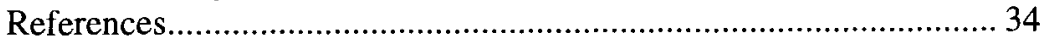




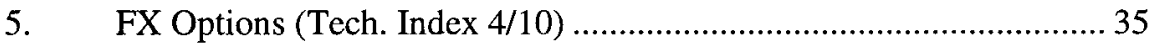

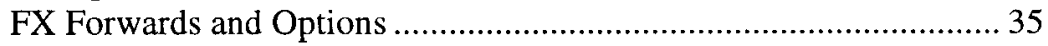

Some Practical Details for FX Options .............................................. 38

Hedging FX Options with Greeks: Details and Ambiguities.............. 39

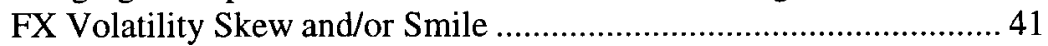

Pricing Barrier Options with Skew................................................... 45

Double Barrier Option: Practical Example .......................................... 47

The "Two-Country Paradox" .......................................................... 48

Quanto Options and Correlations ..................................................... 50

FX Options in the presence of Stochastic Interest Rates ....................51

Numerical Codes, Closed Form Sanity Checks, and Intuition............ 51

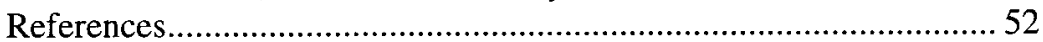

6. Equity Volatility Skew (Tech. Index 6/10) ……..............................53

Put-Call Parity: Theory and Violations ............................................. 54

The Volatility Surface .......................................................................... 55

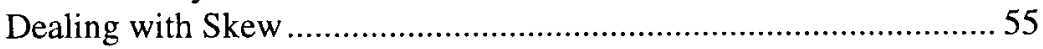

Perturbative Skew and Barrier Options ............................................. 56

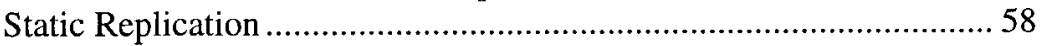

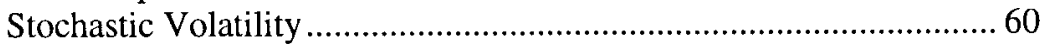

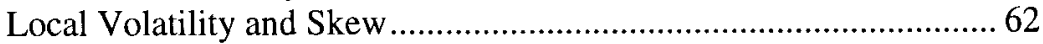

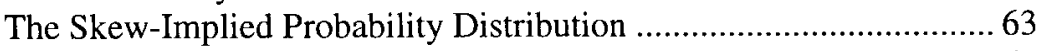

Local vs. Implied Volatility Skew; Derman's Rules of Thumb.......... 63

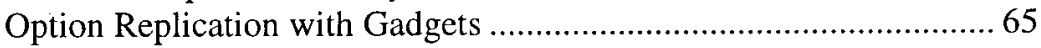

Intuitive Models and Different Volatility Regimes .............................6 68

The Macro-Micro Model and Equity Volatility Regimes.....................6 69

Jump Diffusion Processes .......................................................................69 69

Appendix A: Algorithm for "Perturbative Skew" Approach ............... 69

Appendix B: A Technical Issue for Stochastic Volatility ................... 71

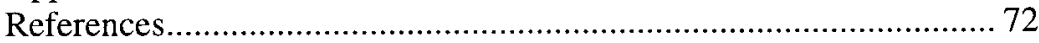

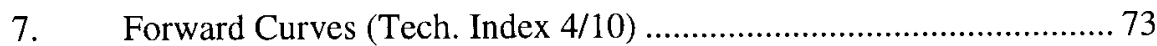

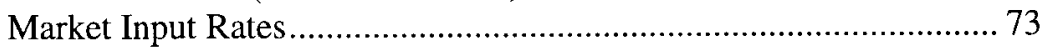

Construction of the Forward-Rate Curve ......................................... 76

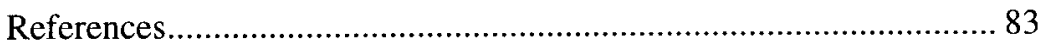

8. Interest-Rate Swaps (Tech. Index 3/10) …....................................... 85

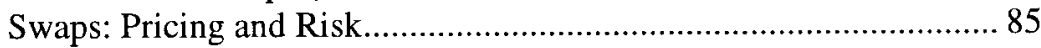

Interest Rate Swaps: Pricing and Risk Details.................................... 91

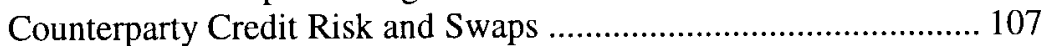

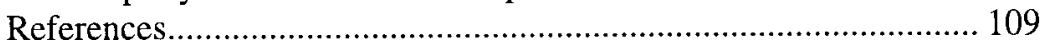

9. Bonds: An Overview (Tech. Index 2/10) ……................................ 111

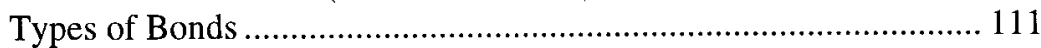

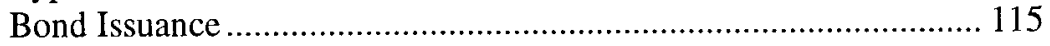




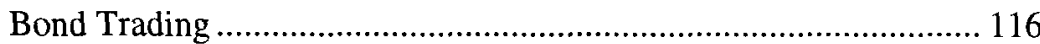

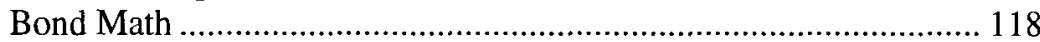

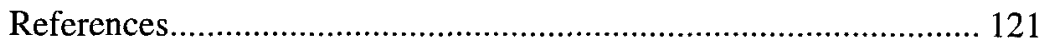

10. Interest-Rate Caps (Tech. Index 4/10) ......................................... 123

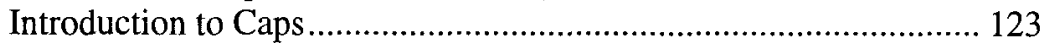

The Black Caplet Formula ............................................................. 125

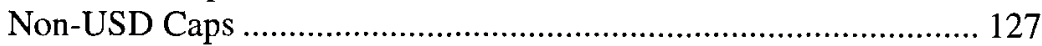

Relations between Caps, Floors, and Swaps................................... 127

Hedging Delta and Gamma for Libor Caps ...................................... 128

Hedging Volatility and Vega Ladders ............................................. 129

Matrices of Cap Prices .................................................................... 131

Prime Caps and a Vega Trap .......................................................... 131

CMT Rates and Volatility Dependence of CMT Products ............... 132

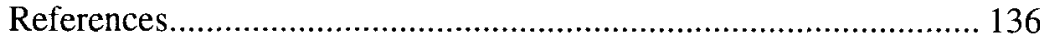

11. Interest-Rate Swaptions (Tech. Index 5/10) ................................... 137

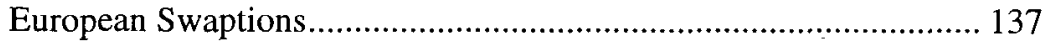

Bermuda/American Swaption Pricing ........................................... 141

Delta and Vega Risk: Move Inputs or Forwards?........................... 143

Swaptions and Corporate Liability Risk Management ..................... 144

Practical Example: A Deal Involving a Swaption. ......................... 146

Miscellaneous Swaption Topics .................................................... 148

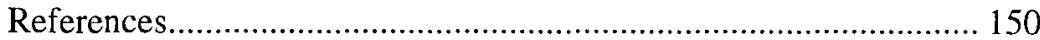

12. Portfolios and Scenarios (Tech. Index 3/10) .................................... 151

Introduction to Portfolio Risk Using Scenario Analysis................... 151

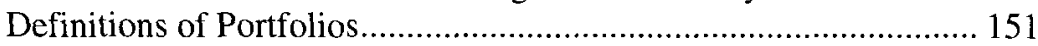

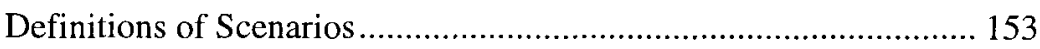

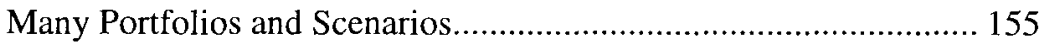

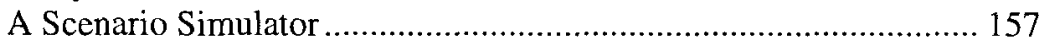

Risk Analyses and Presentations .................................................. 157

PART III: EXOTICS, DEALS, AND CASE STUDIES ........................ 159

13. A Complex CVR Option (Tech. Index 5/10) .................................. 161

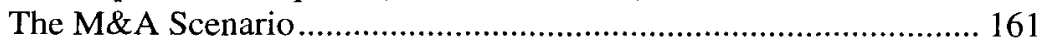

CVR Starting Point: A Put Spread .................................................. 162

CVR Extension Options and Other Complications........................... 162

The Arbs and the Mispricing of the CVR Option............................. 164

A Simplified CVR: Two Put Spreads with Extension Logic ............ 165

Non-Academic Corporate Decision for Option Extension ............... 167

The CVR Option Pricing .............................................................. 169

Analytic CVR Pricing Methodology ................................................. 173 
Some Practical Aspects of CVR Pricing and Hedging ..................... 176

The CVR Buyback ........................................................................... 180

A Legal Event Related to the CVR ……....................................... 180

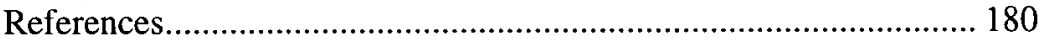

14. Two More Case Studies (Tech. Index 5/10) …............................... 183

Case Study: DECS and Synthetic Convertibles................................. 183

$\mathrm{D}_{123}$ : The Complex DEC Synthetic Convertible ............................... 188

Case Study: Equity Call with Variable Strike and Expiration ........... 193

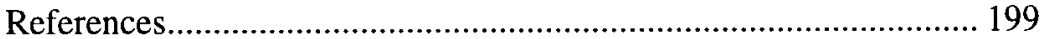

15. More Exotics and Risk (Tech. Index 5/10).................................... 201

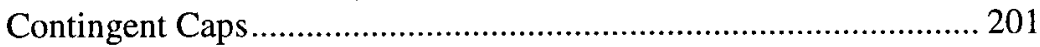

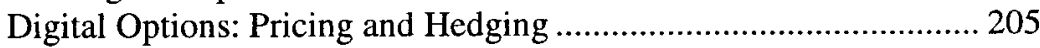

Historical Simulations and Hedging.................................................207

Yield-Curve Shape and Principle-Component Options .................... 209

Principal-Component Risk Measures (Tilt Delta etc.)....................... 210

Hybrid 2-Dimensional Barrier Options-Examples.......................... 211

Reload Options ..................................................................... 214

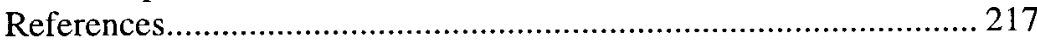

16. A Pot Pourri of Deals (Tech. Index 5/10) ….................................... 219

TIPS (Treasury Inflation Protected Securities)................................. 219

Municipal Derivatives, Muni Issuance, Derivative Hedging ............. 221

Difference Option on an Equity Index and a Basket of Stocks......... 224

Resettable Options: Cliquets .......................................................... 226

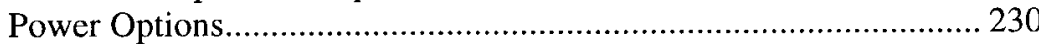

Path-Dependent Options and Monte Carlo Simulation...................... 231

Periodic Caps .............................................................................. 231

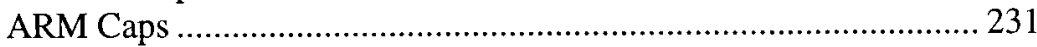

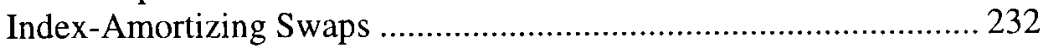

A Hypothetical Repo + Options Deal ............................................. 236

Convertible Issuance Risk ............................................................ 239

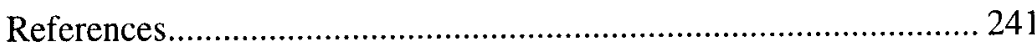

17. Single Barrier Options (Tech. Index 6/10) …................................. 243

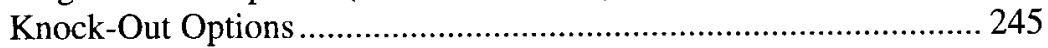

The Semi-Group Property including a Barrier ................................. 247

Calculating Barrier Options ......................................................... 248

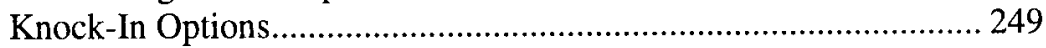

Useful Integrals for Barrier Options .............................................. 251

Complicated Barrier Options and Numerical Techniques ................ 252

A Useful Discrete Barrier Approximation.......................................... 252

"Potential Theory" for General Sets of Single Barriers .................... 253 
Barrier Options with Time-Dependent Drifts and Volatilities.......... 255

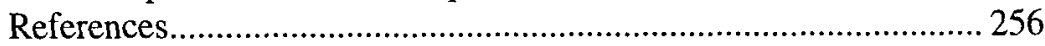

18. Double Barrier Options (Tech. Index 7/10) ..................................... 257

Double Barrier Solution with an Infinite Set of Images ................... 258

Double Barrier Option Pricing ....................................................... 260

Rebates for Double Barrier Options ............................................... 262

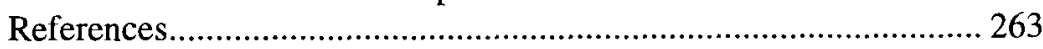

19. Hybrid 2-D Barrier Options (Tech. Index 7/10) …............................ 265

Pricing the Barrier 2-Dimension Hybrid Options …………………. 267

Useful Integrals for 2D Barrier Options ......................................... 268

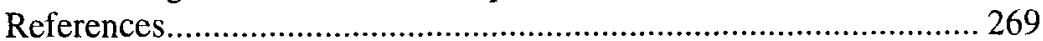

20. Average-Rate Options (Tech. Index 8/10)................................... 271

Arithmetic Average Rate Options in General Gaussian Models....... 272

Results for Average-Rate Options in the MRG Model ...................... 276

Simple Harmonic Oscillator Derivation for Average Options .......... 277

Thermodynamic Identity Derivation for Average Options ............... 278

Average Options with Log-Normal Rate Dynamics........................ 278

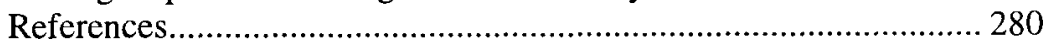

PART IV: QUANTITATIVE RISK MANAGEMENT .......................... 281

21. Fat Tail Volatility (Tech. Index 5/10) ........................................... 283

Gaussian Behavior and Deviations from Gaussian.......................... 283

Outliers and Fat Tails ..................................................................... 284

Use of the Equivalent Gaussian Fat-Tail Volatility ......................... 287

Practical Considerations for the Fat-Tail Parameters ..................... 288

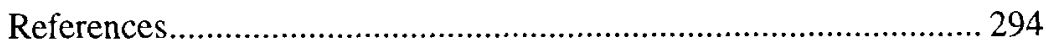

22. Correlation Matrix Formalism; the $\mathcal{N}$-Sphere (Tech. Index 8/10) ... 295

The Importance and Difficulty of Correlation Risk......................... 295

One Correlation in Two Dimensions .............................................. 296

Two Correlations in Three Dimensions; the Azimuthal Angle......... 297

Correlations in Four Dimensions ................................................. 300

Correlations in Five and Higher Dimensions .................................. 301

Spherical Representation of the Cholesky Decomposition ................ 303

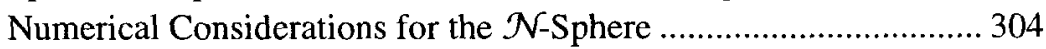

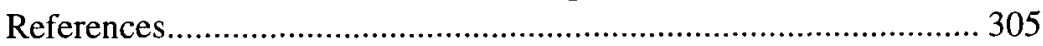

23. Stressed Correlations and Random Matrices (Tech. Index 5/10) ...... 307

Correlation Stress Scenarios Using Data .......................................... 307 
Stressed Random Correlation Matrices ........................................... 313

Random Correlation Matrices Using Historical Data ....................... 313

Stochastic Correlation Matrices Using the $\mathcal{N}$-sphere...................... 314

24. Optimally Stressed PD Correlation Matrices (Tech. Index 7/10) ..... 319

Least-Squares Fitting for the Optimal PD Stressed Matrix................ 321

Numerical Considerations for Optimal PD Stressed Matrix .............. 322

Example of Optimal PD Fit to a NPD Stressed Matrix .................... 323

SVD Algorithm for the Starting PD Correlation Matrix.................... 325

PD Stressed Correlations by Walking through the Matrix................. 328

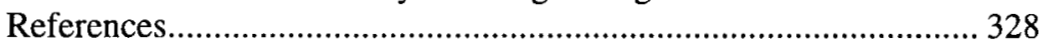

25. Models for Correlation Dynamics, Uncertainties

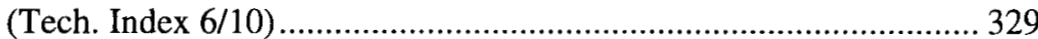

"Just Make the Correlations Zero" Model; Three Versions............... 329

The Macro-Micro Model for Quasi-Random Correlations ................ 331

Correlation Dependence on Volatility .............................................. 335

Implied, Current, and Historical Correlations for Baskets................ 338

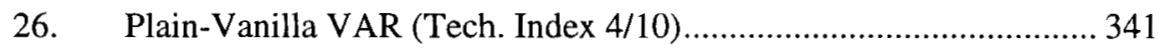

Quadratic Plain-Vanilla VAR and CVARs ..................................... 344

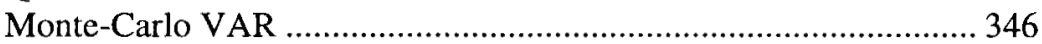

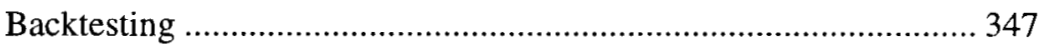

Monte-Carlo CVARs and the CVAR Volatility .............................. 347

Confidence Levels for Individual Variables in VAR......................... 350

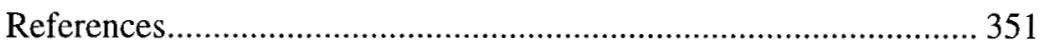

27. Improved/Enhanced/Stressed VAR (Tech. Index 5/10) ................... 353

Improved Plain-Vanilla VAR (IPV-VAR) ................................... 353

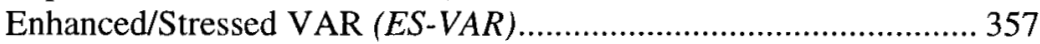

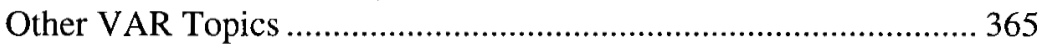

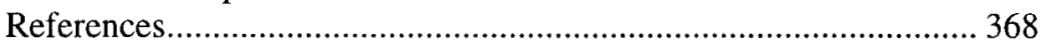

28. VAR, CVAR, CVAR Volatility Formalism (Tech. Index 7/10) ....... 369

Set-up and Overview of the Formal VAR Results............................ 369

Calculation of the Generating Function............................................ 371

VAR, the CVARs, and the CVAR Volatilities ................................ 374

Effective Number of SD for Underlying Variables ......................... 376

Extension to Multiple Time Steps using Path Integrals .................... 378

29. VAR and CVAR for Two Variables (Tech. Index 5/10) .................. 381

The CVAR Volatility with Two Variables....................................... 381

Geometry for Risk Ellipse, VAR Line, CVAR, CVAR Vol.............. 382 
30. Corporate-Level VAR (Tech. Index 3/10)...................................... 387

Aggregation, Desks, and Business Units....................................... 387

Desk CVARs and Correlations between Desk Risks....................... 389

Aged Inventory and Illiquidity ......................................................... 391

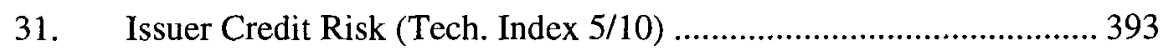

Transition/Default Probability Matrices .......................................... 394

Calculation of Issuer Risk-Generic Case .................................... 399

Example of Issuer Credit Risk Calculation ..................................... 403

Issuer Credit Risk and Market Risk: Separation via Spreads............ 406

Separating Market and Credit Risk without Double Counting ......... 407

A Unified Credit + Market Risk Model............................................ 410

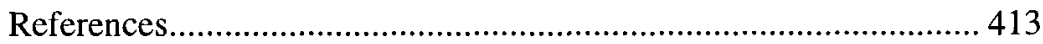

32. Model Risk Overview (Tech. Index 3/10) .......................................415

Summary of Model Risk ................................................................. 415

Model Risk and Risk Management ............................................. 416

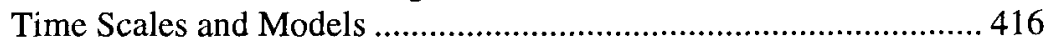

Long-Term Macro Component with Quasi-Random Behavior ........ 417

Liquidity Model Limitations ............................................................. 417

Which Model Should We Use? ...................................................... 418

Model Risk, Model Reserves, and Bid-Offer Spreads..................... 418

Model Quality Assurance ................................................................ 419

Models and Parameters ................................................................ 419

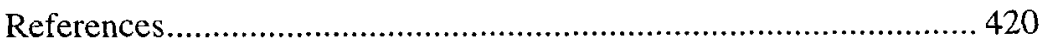

33. Model Quality Assurance (Tech. Index 4/10) ................................. 421

Model Quality Assurance Goals, Activities, and Procedures ........... 421

Model QA: Sample Documentation ................................................ 424

User Section of Model QA Documentation...................................... 425

Quantitative Section of Model QA Documentation........................... 425

Systems Section of Model QA Documentation ............................... 428

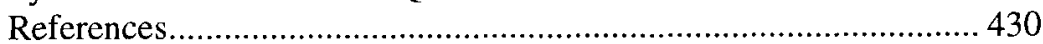

34. Systems Issues Overview (Tech. Index 2/10).................................. 431

Advice and a Message to Non-Technical Managers......................... 431

What are the "Three-Fives Systems Criteria"? .................................. 431

What is the Fundamental Theorem of Systems? .............................. 432

What are Some Systems Traps and Risks?.................................... 432

The Birth and Development of a System......................................... 433

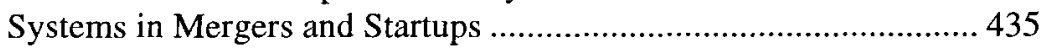

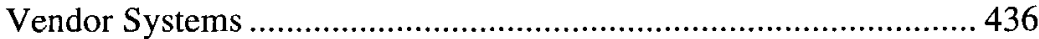

New Paradigms in Systems and Parallel Processing ....................... 437

Languages for Models: Fortran 90, $\mathrm{C}^{++}, \mathrm{C}$, and Others ...................... 438

What's the "Systems Solution"? ......................................................... 440 
Are Software Development Problems Unique to Wall Street? 440

References 440

35. Strategic Computing (Tech. Index 3/10) ....................................441

Introduction and Background ................................................. 442

Illustration of Parallel Processing for Finance ................................ 442

Some Aspects of Parallel Processing .......................................... 443

Technology, Strategy and Change............................................ 446

References....................................................................... 447

36. Qualitative Overview of Data Issues (Tech. Index 2/10)................ 449

Data Consistency ...................................................................... 449

Data Reliability ...................................................................... 450

Data Completeness........................................................... 450

Data Vendors ....................................................................... 450

Historical Data Problems and Data Groups................................. 451

Preparation of the Data ........................................................... 451

Bad Data Points and Other Data Traps.................................... 451

37. Correlations and Data (Tech. Index 5/10) ..................................453

Fluctuations and Uncertainties in Measured Correlations .............. 453

Time Windowing ................................................................ 454

Correlations, the Number of Data Points, and Variables ................456 456

Intrinsic and Windowing Uncertainties: Example ........................ 458

Two Miscellaneous Aspects of Data and Correlations .................. 460

References........................................................................ 460

38. Wishart's Theorem and Fisher's Transform (Tech. Index 9/10)...... 461

Warm Up: The Distribution for a Volatility Estimate ................... 462

The Wishart Distribution........................................................ 464

The Probability Function for One Estimated Correlation ................ 465

Fisher's Transform and the Correlation Probability Function ......... 466

The Wishart Distribution Using Fourier Transforms...................... 468

References................................................................. 473

39. Economic Capital (Tech. Index 4/10) …........................................ 475

Basic Idea of Economic Capital ............................................. 475

The Classification of Risk Components of Economic Capital......... 479

Exposures for Economic Capital: What Should They Be? .............. 480

Attacks on Economic Capital at High CL ................................... 480

Allocation: Standalone, CVAR, or Other? ................................ 481

The Cost of Economic Capital .................................................. 483

An Economic-Capital Utility Function......................................... 484

Sharpe Ratios .................................................................... 484

Revisiting Expected Losses; the Importance of Time Scales .......... 485 
Cost Cutting and Economic Capital .............................................. 487

Traditional Measures of Capital, Sharpe Ratios, Allocation............. 487

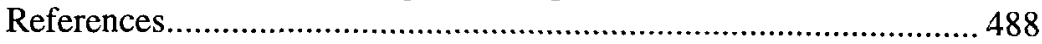

40. Unused-Limit Risk (Tech. Index 6/10) .............................................489

General Aspects of Risk Limits...................................................... 489

The Unused Limit Risk Model: Overview ........................................ 491

Unused Limit Economic Capital for Issuer Credit Risk ................... 497

\section{PART V: PATH INTEGRALS, GREEN FUNCTIONS,}

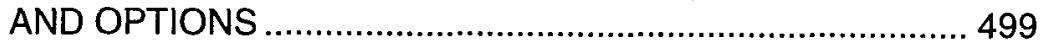

41. Path Integrals and Options: Overview (Tech. Index 4/10).................501

42. Path Integrals and Options I: Introduction (Tech. Index 7/10) .........505

Introduction to Path Integrals ........................................................ 506

Path-Integral Warm-up: The Black Scholes Model.......................... 509

Connection of Path Integral with the Stochastic Equations ............... 521

Dividends and Jumps with Path Integrals........................................ 523

Discrete Bermuda Options .............................................................. 530

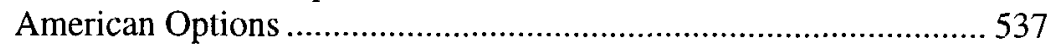

Appendix A: Girsanov's Theorem and Path Integrals ...................... 538

Appendix B: No-Arbitrage, Hedging and Path Integrals .................. 541

Appendix C: Perturbation Theory, Local Volatility, Skew................ 546

Figure Captions for this Chapter .................................................. 546

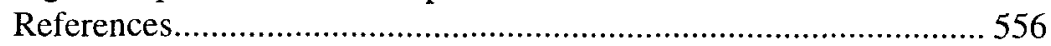

43. Path Integrals and Options II: Interest-Rates (Tech. Index 8/10)..... 559

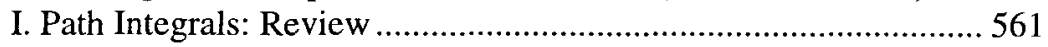

II. The Green Function; Discretized Gaussian Models ..................... 562

III. The Continuous-Time Gaussian Limit ..................................... 566

IV. Mean-Reverting Gaussian Models ..............................................569

V. The Most General Model with Memory ..................................... 574

VI. Wrap-Up for this Chapter ...................................................... 578

Appendix A: MRG Formalism, Stochastic Equations, Etc.............. 579

Appendix B: Rate-Dependent Volatility Models.............................. 586

Appendix C: The General Gaussian Model With Memory............... 589

Figure Captions for This Chapter .................................................. 591

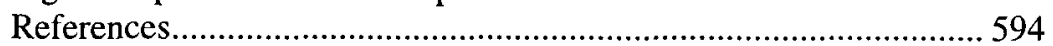

44. Path Integrals and Options III: Numerical (Tech. Index 6/10).......... 597

Path Integrals and Common Numerical Methods ............................. 598

Basic Numerical Procedure using Path Integrals ...............................600

The Castresana-Hogan Path-Integral Discretization......................... 603 
Some Numerical Topics Related to Path Integrals ........................... 608

A Few Aspects of Numerical Errors ................................................614

Some Miscellaneous Approximation Methods................................... 618

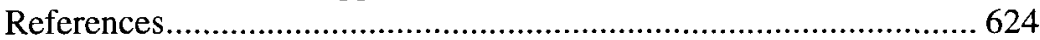

45. Path Integrals and Options IV: Multiple Factors

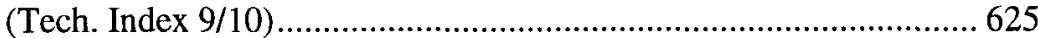

Calculating Options with Multidimensional Path Integrals ............... 628

Principal-Component Path Integrals................................................ 629

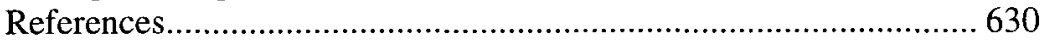

46. The Reggeon Field Theory, Fat Tails, Chaos (Tech. Index 10/10) ...631 Introduction to the Reggeon Field Theory (RFT) ..............................631

Summary of the RFT in Physics........................................................632 632

Aspects of Applications of the RFT to Finance.................................637

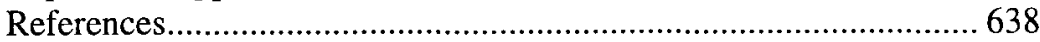

PART VI: THE MACRO-MICRO MODEL (A RESEARCH TOPIC) ....... 639

47. The Macro-Micro Model: Overview (Tech. Index 4/10) .................. 641

Explicit Time Scales Separating Dynamical Regions.........................641 64

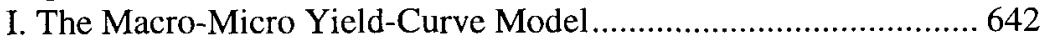

II. Further Developments in the Macro-Micro Model ....................... 646

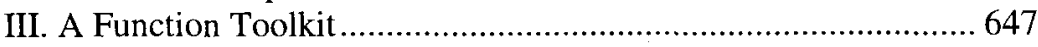

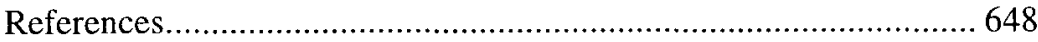

48. A Multivariate Yield-Curve Lognormal Model (Tech. Index 6/10) . 649

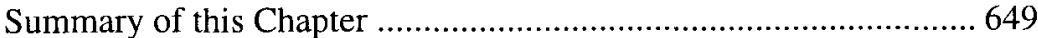

The Problem of Kinks in Yield Curves for Models ...........................650

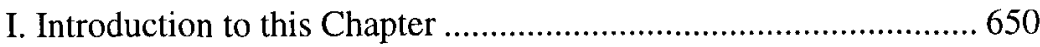

IIA. Statistical Probes, Data, Quasi-Equilibrium Drift ...................... 653

IIB. Yield-Curve Kinks: Bête Noire of Yield Curve Models ............. 655

III. EOF / Principal Component Analysis............................................ 656

IV. Simpler Lognormal Model with Three Variates...........................658

V. Wrap-Up and Preview of the Next Chapters ............................... 659

Appendix A: Definitions and Stochastic Equations............................659

Appendix B: EOF or Principal-Component Formalism...................... 662

Figures: Multivariate Lognormal Yield-Curve Model.......................667

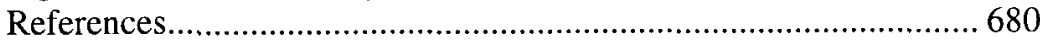

49. Strong Mean-Reverting Multifactor YC Model (Tech. Index 7/10) . 681

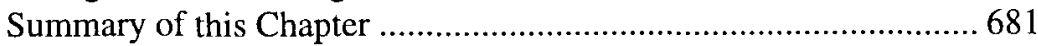

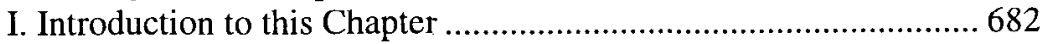

II. Cluster Decomposition Analysis and the SMRG Model............... 685 
III. Other Statistical Tests and the SMRG Model ..............................691

IV. Principal Components (EOF) and the SMRG Model ................. 694

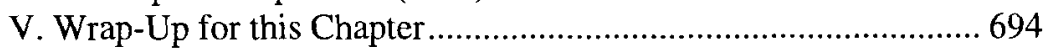

Appendix A: Definitions and Stochastic Equations..........................695

Appendix B: The Cluster-Decomposition Analysis (CDA).............. 697

Figures: Strong Mean-Reverting Multifactor Yield-Curve Model ... 701

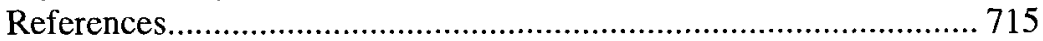

50. The Macro-Micro Yield-Curve Model (Tech. Index 5/10).............. 717

Summary of this Chapter ........................................................... 717

I. Introduction to this Chapter ..................................................... 718

Prototype: Prime (Macro) and Libor (Macro + Micro) ...................... 720

II. Details of the Macro-Micro Yield-Curve Model ……................. 721

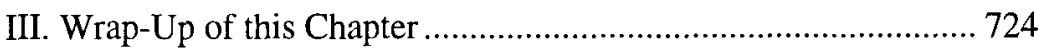

Appendix A. No Arbitrage and Yield-Curve Dynamics................... 725

Figures: Macro-Micro Model............................................................ 726

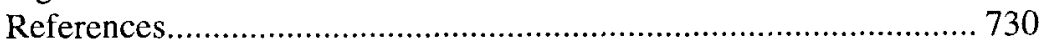

51. Macro-Micro Model: Further Developments (Tech. Index 6/10) .... 731

Summary of This Chapter ……...................................................... 731

The Macro-Micro Model for the FX and Equity Markets ................ 733

Macro-Micro-Related Models in the Economics Literature .............. 735

Related Models for Interest Rates in the Literature .......................... 735

Related Models for FX in the Literature........................................... 736

Formal Developments in the Macro-Micro Model ............................ 737

No Arbitrage and the Macro-Micro Model: Formal Aspects............ 739

Hedging, Forward Prices, No Arbitrage, Options (Equities) ............. 741

Satisfying the Interest-Rate Term-Structure Constraints .................. 744

Other Developments in the Macro-Micro Model ............................. 745

Derman's Equity Regimes and the Macro-Micro Model.................. 745

Seigel's Nonequilibrium Dynamics and the MM Model.................. 745

Macroeconomics and Fat Tails (Currency Crises).......................... 746

Some Remarks on Chaos and the Macro-Micro Model.................... 747

Technical Analysis and the Macro-Micro Model ............................ 749

The Macro-Micro Model and Interest-Rate Data 1950-1996 ........... 750

Data, Models, and Rate Distribution Histograms ............................ 751

Negative Forwards in Multivariate Zero-Rate Simulations ............... 752

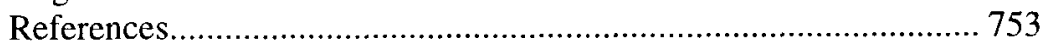

52. A Function Toolkit (Tech. Index 6/10) ......................................... 755

Time Thresholds; Time and Frequency; Oscillations ...................... 756

Summary of Desirable Properties of Toolkit Functions ................... 757

Construction of the Toolkit Functions.............................................. 757

Relation of the Function Toolkit to Other Approaches................... 762

Example of Standard Micro "Noise" Plus Macro "Signal" .............. 764 
The Total Macro: Quasi-Random Trends + Toolkit Cycles 767

Short-Time Micro Regime, Trading, and the Function Toolkit ........ 768

Appendix: Wavelets, Completeness, and the Function Toolkit ......... 769

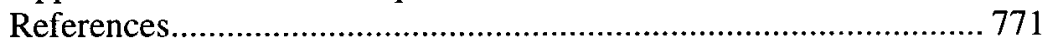

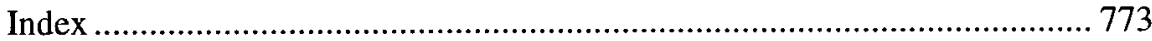




\section{Acknowledgements}

First, I owe a big debt of gratitude to Andy Davidson, Santa Federico, and Les Seigel, all super quants, for their support. The work of two colleagues contributed to this book: Alan Beilis (who collaborated with me on the Macro-Micro model), and Juan Castresana (who implemented numerical path-integral discretization). I thank them and the other members of the quant groups I managed over the years for their dedication and hard work. Many other colleagues helped and taught me, including quants, systems people, traders, managers, salespeople, and risk managers. I thank them all. Some specific acknowledgements are in the text.

Rich Lee, extraordinary FX systems person killed on 9/11, is remembered.

I thank Global Risk Management, Salomon Smith Barney, Citigroup for a nine-month leave of absence during 2002-03 when part of this book was written.

The Centre de Physique Théorique (CNRS Marseille, France) granted a leave of absence during my first few years on the Street, for which I am grateful.

The editors at World Scientific have been very helpful.

I especially thank my family for their encouragement, including my daughter Sarah and son David. I could not have done any of this without the constant understanding and love from my wife Lynn. 